九州大学学術情報リポジトリ

Kyushu University Institutional Repository

\title{
Productioin of Tetraploid Forms of Acid Citrus Cultivars by Top Grafting of Shoots with Sprouting Axially Buds Treated with Colchicine
}

Wakana, Akira

Laboratory of Horticultural Science, Divisioin of Agricultural Botany, Department of Plant Resources, Faculty of Agriculture, Kyushu University

Park, Sung Min

Laboratory of Horticultural Science, Divisioin of Applied Plant Sciences, College of Agriculture and Life Sciences, Kangwon National University, Korea

Hanada, Nobuak i

Laboratory of Fruit Tree Science, University Farm, Faculty of Agriculture, Kyushu University

Fukudome, Isao

Laboratory of Fruit Tree Science, University Farm, Faculty of Agriculture, Kyushu University 他

https://doi.org/10.5109/4625

出版情報：九州大学大学院農学研究院紀要. 50 (1)，pp.93-102，2005-02-01. Faculty of Agriculture， Kyushu University

バージョン :

権利関係: 


\title{
Production of Tetraploid Forms of Acid Citrus Cultivars by Top Grafting of Shoots with Sprouting Axially Buds Treated with Colchicine
}

\author{
Akira WAKANA ${ }^{1,2 *}$, Nobuaki HANADA ${ }^{3}$, Sung Min PARK ${ }^{1,4}$, \\ Isao FUKUDOME ${ }^{3}$ and Kohei KAJIWARA ${ }^{3}$
' Laboratory of Horticultural Science, Division of Agricultural Botany, Department of Plant Resources, Faculty of Agriculture, Kyushu University, Fukuoka 812-8581, Japan \\ (Received November 5, 2004 and accepted November 11, 2004)
}

\begin{abstract}
To induce the tetraploid forms of three diploid acid Citrus cultivars ( $2 n=2 x=18$ ), 'Yuzu' (C. junos), 'Kizu'(C. kizu) and 'Hanayu' (C. hanaju), sections of one-year-old spring shoots with sprouting axillary buds were treated with various concentrations of colchicine and immediately top-grafted on 30-year-old satsuma mandarin trees at the beginning of April. Characteristics of the plants developed from the top grafted scions were scored five years after the treatments. Tetraploid forms of the cultivars, which were certified by tetraploid chromosome number in their seedlings, were derived from the shoot sections treated with $0.05-0.4 \%$ colchicine solutions for 12 hours for 'Yuzu', $0.05-0.4 \%$ for 6 hours for 'Kizu' and 0.1 and $0.2 \%$ for 6 hours for 'Hanayu'. As compared with the original plants, these colchicine-induced tetraploid plants produced large flowers, fruits with thick rind, large oil gland and large seeds, and showed high leaf shape index (leaf width / leaf length). The large seeds from open-pollinated tetraploid plants showed the same degree of polyembryony as seeds from their original diploid cultivars, and their seedlings were tetraploid. These results suggested not only that the tetraploid forms of the three cultivars can be directly used for breeding of triploid seedless acid citrus cultivars as seed or pollen parents, but also that the present method is superior to the other methods to produce citrus tetraploid forms directly applicable for triploid breeding at two to four years after colchicine treatments.
\end{abstract}

\section{INTRODUCTION}

Triploid Citrus plants with high parthenocarpic ability are of great interest for establishing seedless cultivars, because of their horticulturally favorable characteristics and high productivity. Soost and Cameron $(1980,1985)$ firstly bred two seedless cultivars 'Oroblanco' and 'Melogold' that are triploid pummelo-grapefruit hybrids from $2 \mathrm{x} \times 4 \mathrm{x}$ crosses. However, introduction of triploid Citrus cultivars has so far been very limited.

For the breeding of triploid Citrus cultivars, literatures suggest two methods, i.e., usage of diploid megagametophytes of tetraploids and diploids, and usage of diploid

\footnotetext{
2 Laboratory of Fruit Tree Science, Division of Agricultural Ecology, Faculty of Agriculture, Kyushu University, Fukuoka 811-2307, Japan

3 Laboratory of Fruit Tree Science, University Farm, Faculty of Agriculture, Kyushu University, Fukuoka 811-2307, Japan

4 Laboratory of Horticultural Science, Division of Applied Plant Sciences, College of Agriculture and Life Sciences, Kangwon National University, Chunchon, Korea

* Corresponding author (E-mail: wakana@agr.kyushu-u.ac.jp)
} 
pollen of tetraploids. The percentage of diploid megagametophytes or unreduced eggs varied from less than $1 \%$ to about $25 \%$ in diploid Citrus cultivars tested (Esen and Soost, 1971; Geraci et al., 1975; Wakana et al., 1982). In Japanese acid citrus cultivars tested, however, the rates were so low that we might not use them as triploid breeding materials (Wakana, unpublished data). Thus, the usage of tetraploids seems to be the best method for the production of triploid acid citrus plants.

Most tetraploid Citrus plants that have been established were obtained as variant nucellar seedlings in seedling populations grown for other purposes (Soost and Cameron, 1975). Generally, tetraploid frequency varied from less than $1 \%$ to $3 \%$ in the seedling populations (Soost, 1987). In addition to the low frequencies, the tetraploid nucellar seedlings have very long juvenile periods from five to more than ten years as is observed in diploid nucellar ones. Hence, induction of tetraploid sports on shoots of target diploid cultivars is considered to be the most efficient method for shortening the periods.

After the work of Tachikawa (1971), tetraploids were derived from diploid cultivars treated with colchicine. Barrett (1974) successfully induced tetraploids form diploid Citrus cultivars as well as periclinal ploidy chimeras by colchicine treatment on the sprouting axillary buds. In polyembryonic diploid cultivars, Gmitter and Ling (1991) recovered non-chimerical tetraploids from the undeveloped ovules cultured on the medium supplemented with 0.01 and $0.1 \%$ colchicine. Tetraploid plants were also produced by somatic hybridization between polyembryonic cultivars and between polyembryonic and monoembryonic cultivars using embryogenic callus from polyembryonic cultivars (Kobayashi and Ohgawara, 1988; Grosser and Gmitter, 1990). Presence of barrier of nucellar embryony in these tetraploids, however, led them to the use as pollen parents, since production of triploids is very difficult or at extremely low frequencies (Soost, 1987).

Although most acid citrus cultivars are moderately or highly polyembryonic, some acid citrus cultivars such as 'Yuzu', 'Hanayu' and 'Lisbon' lemon show very low degree of polyembryony and produce monoembryonic seeds and zygotic seedlings with high frequencies. Therefore, they are useful not only as pollen parents but also as seed parents for breeding triploid Citrus cultivars.

The aim of this study is to develop most convenient and efficient method of colchicine treatment to scions and subsequent top working, by which we produce tetraploid forms of diploid acid citrus cultivars that will be directly used for triploid breeding as seed and/or pollen parents as early as possible.

\section{MATERIALS AND METHODS}

\section{Plant materials}

Three diploid acid citrus cultivars $(2 \mathrm{n}=2 \mathrm{x}=18)$, 'Yuzu' (C. junos Sibb. ex Tanaka), 'Kizu'(C. kizu hort. ex Y. Tanaka) and 'Hanayu' (C. hanaju hort. ex Shirai) were used as plant materials to produce their tetraploid forms. These cultivars were about 30-year-old trees grown at Sasaguri orchard of the University Farm, Kyushu University, Fukuoka. 'Yuzu' and 'Hanayu' showing low degree of polyembryony produce 2.3 and 1.2 embryos per seed in average, whereas highly polyembryonic 'Kizu' produces $>10.0$ embryos per seed in average. 'Yuzu' is a leading cultivar of acid citrus cultivated in Japan, while 'Kizu' 
and 'Hanayu' are miner ones. Tetraploid 'Kizu', 1-No.5, was also prepared to demonstrate the characteristics of tetraploid plants

\section{Colchicine treatment}

When axillary bud break occurred in shoots of these cultivars at early to middle in April 1996, sections ( $5 \mathrm{~cm}$ in length) were excised from one-year-old spring shoots and trimmed so that at least three axillary buds remained on the shoot sections. The trimmed sections were immersed in colchicine solutions supplemented with a few drops of Tween 20 per litter. The immersion treatment was made in combination with various concentrations of colchicine and different immersion times, i.e., $0.05,0.1,0.2,0.4$ and $0.8 \%$ for 'Kizu' and 'Hanayu', 0.05, 0.1, 0.2 and 0.4\% for 'Yuzu'; 4, 8, 12 and 16 hours for 'Yuzu' and 6 hours for 'Kizu' and 'Hanayu'. During the immersion treatment, vessels with 15 sections each were shacked 60 times per minute. The colchicine-treated shoot sections (scions) were rinsed twice with water, and immediately grafted on blanches of about 30-year-old 'Okitsu Wase Unshiu' (C. unshiu Marc.), covered with TX film and allowed to growth.

\section{Morphology of shoots}

After the first flower initiated on the shoots developing from the scions, the morphology of shoots was compared with that of the original plants. The characteristics of flower buds and flowers were also observed and photographed. Five mature fruits from open pollination were collected from each of the colchicine-induced tetraploid-like shoots at October. Then, the weight of fruits and seeds, number of perfect seeds and rind thickness were scored.

For the examination of leaf characters, ten typical leaves were collected from each of the colchicine-induced tetraploid-like plants and the original diploid cultivars. Then, their wing leaves were removed, and width and length of these leaves were measured and leaf shape index (width / length) was calculated.

\section{Chromosome observation}

The perfect seeds were divided into two categories, large and small. For chromosome observation, only large seeds were randomly chosen in each of the original cultivars and plants with tetraploid-like morphology. Seed coat of the large perfect seeds was removed with forceps. The embryos extracted from each seed with forceps were placed on wet filter paper and incubated at $25^{\circ} \mathrm{C}$. Root tips of the germinated embryos were collected and the chromosome number in the root tip cells was counted under a microscope according to the procedure reported by Park et al. (1999). One embryo extracted from three large perfect seed each was used for chromosome number observation.

\section{RESULTS}

Some of the shoots developing from colchicine-treated scions showed sectorial-chimera-like or mixoploid-like morphology up to one or two years after the grafting. However, plants with this morphology disappeared by five year after grafting.

Of 340 scions treated with various concentrations of colchicine and grafted on satsuma mandarin trees, 123 produced plants five years after the grafting or five-year-old 
branches. In the plants, flower formation and fruit set started from two years after grafting and were observed at almost all of the plants by five years after the grafting.

\section{Rate of plants with tetraploid-like morphology}

Of 240 colchicine-treated scions of 'Yuzu', five scions immersed for 12 hours produced plants with typical morphology of tetraploid (Table 1). Each of the five scions produced one tetraploid-like plant, and one of the five also produced one additional plant without any morphological variation. The colchicine concentrations that resulted in tetraploid-like plant formation were $0.05,0.10,0.20$ and $0.40 \%$ (Table 1 ).

Of 50 'Kizu' scions, six scions treated with $0.05-0.40 \%$ colchicine solutions for six hours produced tetraploid-like plants (Table 2). One scion immersed in $0.05 \%$ and one scion immersed in $0.10 \%$ colchicine solution produced two shoots each. Only one of the two shoots developed into plants with tetraploid-like morphology.

Of 50 'Hanayu' scions, one scion immersed in $0.05 \%$ colchicine solution for 6 hours and four scions immersed in $0.10 \%$ colchicine solution for 6 hours developed into plants with the typical morphology of tetraploid (Table 2). In 'Hanayu' and 'Kizu', shoots successfully developed from about half of the scions treated with low concentration of colchicine (0.05-0.20\%). However, no shoots developed from scions treated with $0.80 \%$ of colchicine in the both cultivars and only two shoots developed from only two scions

Table 1. Number of diploid and tetraploid plants successfully developing from 'Yuzu' scions treated with different concentration of colchicine solutions in combination with different treatment time. The results were scored five years after the grafting.

\begin{tabular}{|c|c|c|c|c|c|c|}
\hline \multirow{2}{*}{$\begin{array}{c}\text { Exposure } \\
\text { time to } \\
\text { colchicine (hr) } \\
\text { (hr) }\end{array}$} & \multirow{2}{*}{$\begin{array}{c}\text { Concentration } \\
\text { of } \\
\text { colchicine (\%) } \\
\text { (\%) }\end{array}$} & \multirow{2}{*}{$\begin{array}{l}\text { No. of } \\
\text { scions } \\
\text { treated }\end{array}$} & \multicolumn{4}{|c|}{$\begin{array}{l}\text { No. of scions producing shoots with } \\
\text { indicated ploidy (No. of shoots) }\end{array}$} \\
\hline & & & $2 x$ & $4 x$ & $2 \mathrm{x}$ and $4 \mathrm{x}$ & Total \\
\hline \multirow[t]{4}{*}{4} & 0.05 & 15 & 9 & 0 & 0 & 9 \\
\hline & 0.10 & 15 & 6 & 0 & 0 & 6 \\
\hline & 0.20 & 15 & 3 & 0 & 0 & 3 \\
\hline & 0.40 & 15 & 7 & 0 & 0 & 7 \\
\hline \multirow[t]{4}{*}{8} & 0.05 & 15 & 3 & 0 & 0 & 3 \\
\hline & 0.10 & 15 & 3 & 0 & 0 & 3 \\
\hline & 0.20 & 15 & 2 & 0 & 0 & 2 \\
\hline & 0.40 & 15 & 1 & 0 & 0 & 1 \\
\hline \multirow[t]{4}{*}{12} & 0.05 & 15 & 6 & 1 & 0 & 7 \\
\hline & 0.10 & 15 & 7 & 1 & 0 & 8 \\
\hline & 0.20 & 15 & 8 & 1 & $1(1 / 2)^{\prime \prime}$ & 10 \\
\hline & 0.40 & 15 & 4 & 1 & 0 & 5 \\
\hline \multirow[t]{4}{*}{16} & 0.05 & 15 & 11 & 0 & 0 & 11 \\
\hline & 0.10 & 15 & 3 & 0 & 0 & 3 \\
\hline & 0.20 & 15 & 2 & 0 & 0 & 2 \\
\hline & 0.40 & 15 & 3 & 0 & 0 & 3 \\
\hline Total & - & 240 & 78 & 4 & 1 & 83 \\
\hline
\end{tabular}

"Ploidy was estimated by their morphological characteristics. "Two shoots, one $2 \mathrm{x}$ and one $4 \mathrm{x}$, developed from one axillary bud on the scion. 
Table 2. Number of diploid and tetraploid plants successfully developing from grafted scions treated with different concentration of colchicine solutions for six hours. The results were scored five years after the grafting.

\begin{tabular}{|c|c|c|c|c|c|c|}
\hline \multirow{2}{*}{ Cultivar } & \multirow{2}{*}{$\begin{array}{c}\text { Concentration } \\
\text { of } \\
\text { colchicine } \\
(\%)\end{array}$} & \multirow{2}{*}{$\begin{array}{l}\text { No. of } \\
\text { scions } \\
\text { treated }\end{array}$} & \multicolumn{4}{|c|}{$\begin{array}{l}\text { No. of scions forming shoots with } \\
\text { indicated ploidy }{ }^{a}\end{array}$} \\
\hline & & & $2 \mathrm{x}$ & $4 \mathrm{x}$ & $\begin{array}{c}2 \mathrm{x} \& 4 \mathrm{x} \\
\left(\text { No. }{ }^{\mathrm{b}}\right)\end{array}$ & Total \\
\hline \multirow[t]{6}{*}{ Kizu } & 0.05 & 10 & 5 & 0 & $1(1 / 2)$ & 6 \\
\hline & 0.10 & 10 & 4 & 0 & $1(1 / 2)$ & 5 \\
\hline & 0.20 & 10 & 4 & 3 & $0(-)$ & 7 \\
\hline & 0.40 & 10 & 1 & 1 & $0 \quad(-)$ & 2 \\
\hline & 0.80 & 10 & 0 & 0 & $0(-)$ & 0 \\
\hline & Total & 50 & 14 & 4 & $2(2 / 4)$ & 20 \\
\hline \multicolumn{7}{|l|}{ Hanayu } \\
\hline & 0.05 & 10 & 5 & 0 & $0(-)$ & 5 \\
\hline & 0.10 & 10 & 3 & 1 & $0(-)$ & 4 \\
\hline & 0.20 & 10 & 5 & 2 & $2(2 / 5)$ & 9 \\
\hline & . $\quad 0.40$ & 10 & 2 & 0 & $0(-)$ & 2 \\
\hline & 0.80 & 10 & 0 & 0 & $0 \quad(-)$ & 0 \\
\hline & Total & 50 & 15 & 3 & $2(2 / 5)$ & 20 \\
\hline
\end{tabular}

${ }^{a}$ Ploidy was estimated by their morphological characteristics. ${ }^{\mathrm{D}} \mathrm{A}$ total number of $4 \mathrm{x}$ shoots / a total number of $2 \mathrm{x}$ shoots.

treated with $0.40 \%$ colchicine in each of the cultivars.

\section{Ploidy of seedlings}

Chromosome numbers in the root tip cells of seedlings from the tetraploid-like plants were 38 in all seedlings examined. Hence, the tetraploid-like plants were certified to be tetraploid plants in which at least the second germ layer is tetraploid useful for triploid citrus breeding.

\section{4x Plant morphology}

Compared with the original diploid cultivars, the colchicine-induced tetraploid plants had (1) thick and wide dark-green leaves (Fig. 1), (2) very large flower buds, anthers and pistils (Fig. 2), and (3) thick and large petals and calyxes (Fig. 2). The plants produced larger fruits with larger seeds, thicker rind and larger oil grand than the original diploid cultivars (Table 3, Fig. 3). The induced tetraploid plants of each cultivar were morphologically uniform and, except those of 'Hanayu', showed the same extent of tree vigor as the original diploid. 'Hanayu' tetraploids showed horizontally oriented growth and a slower growth rate than diploid.

There was relatively large variation in leaf length between and among the original and colchicine-induced tetraploid plants, probably due to the extent of tree vigor. However, significant difference was observed in leaf width between them, i.e., the leaf width in tetraploids was 1.13-1.50 times as wide as that in the original diploid cultivars. The difference was more clearly detected by the usage of leaf shape index (width / length): the indices in each of the induced tetraploids of 'Yuzu', 'Hanayu' and 'Kizu' were almost simi- 

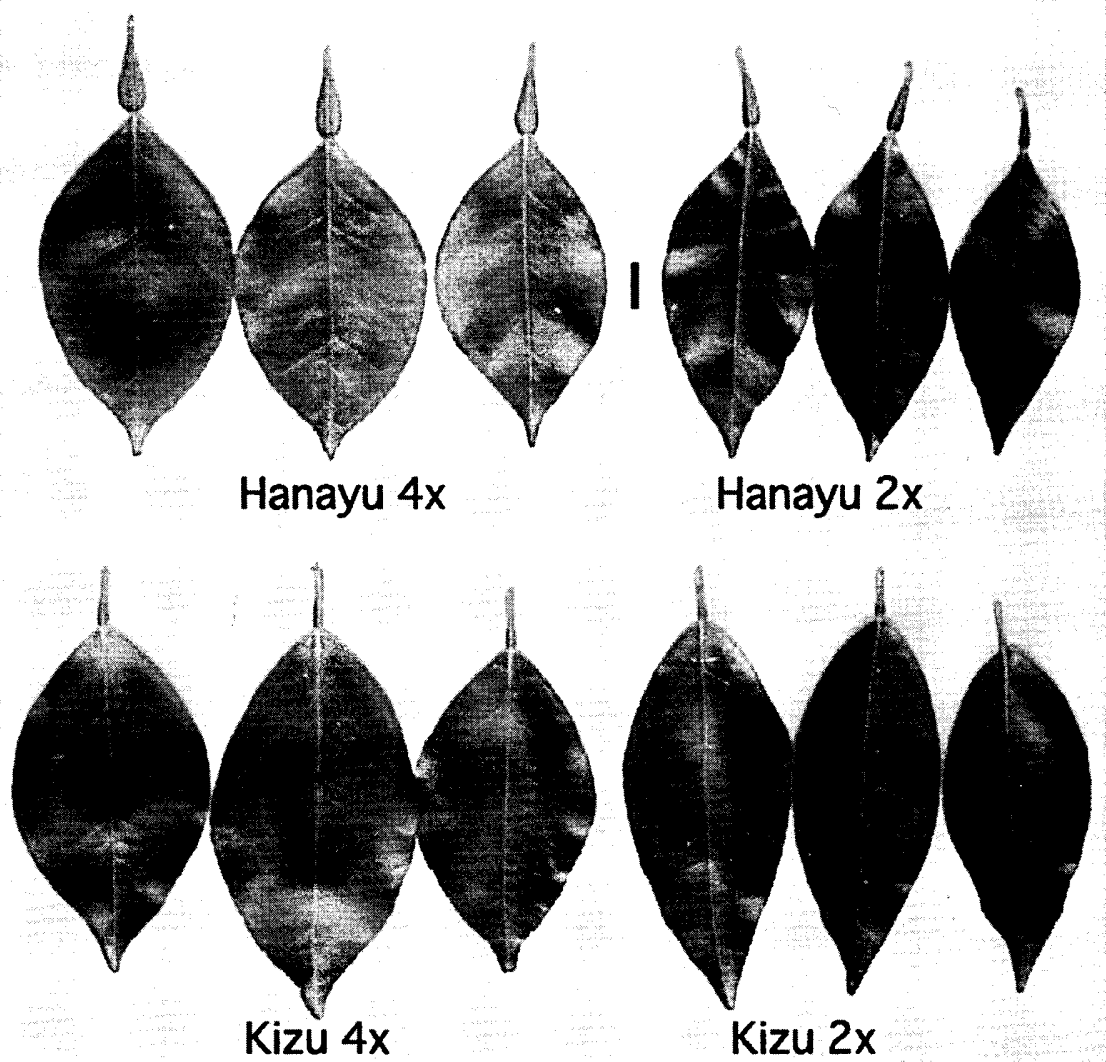

Fig. 1. Leaf morphology in colchicine-induced tetraploids (left) and the original diploid (right) 'Hanayu' and 'Kizu'. The vertical bar indicates $1 \mathrm{~cm}$.

lar and were about 1.3 times higher than those in the original diploid cultivars (Table 3).

Fruits of the induced tetraploid plants were larger than those of the original diploid in any cultivars and had very thicker rind, which was $1.3,1.4$ and 1.7 times thicker than that of the original diploid 'Yuzu', 'Hanayu' and 'Kizu' respectively (Table 3). Compared with the original cultivars, average weight of large seeds of the tetraploid plants was about 1.1 times heavy for 'Yuzu' and 'Hanayu', and was about 1.3 times heavy for 'Kizu' (Table 3). The seeds from the induced tetraploid plants contained almost the same number of embryos as those from the original diploid cultivars, i.e., 1.11 for 'Hanayu', 2.35 for 'Yuzu' and $>10$ for 'Kizu'. The induced tetraploid plants contained small plump seeds with relatively high frequencies as compared with the original diploids (Table 3). This phenomenon seemed to be related to pollination of the tetraploid plants with diploid plants locating adjacent to them. 

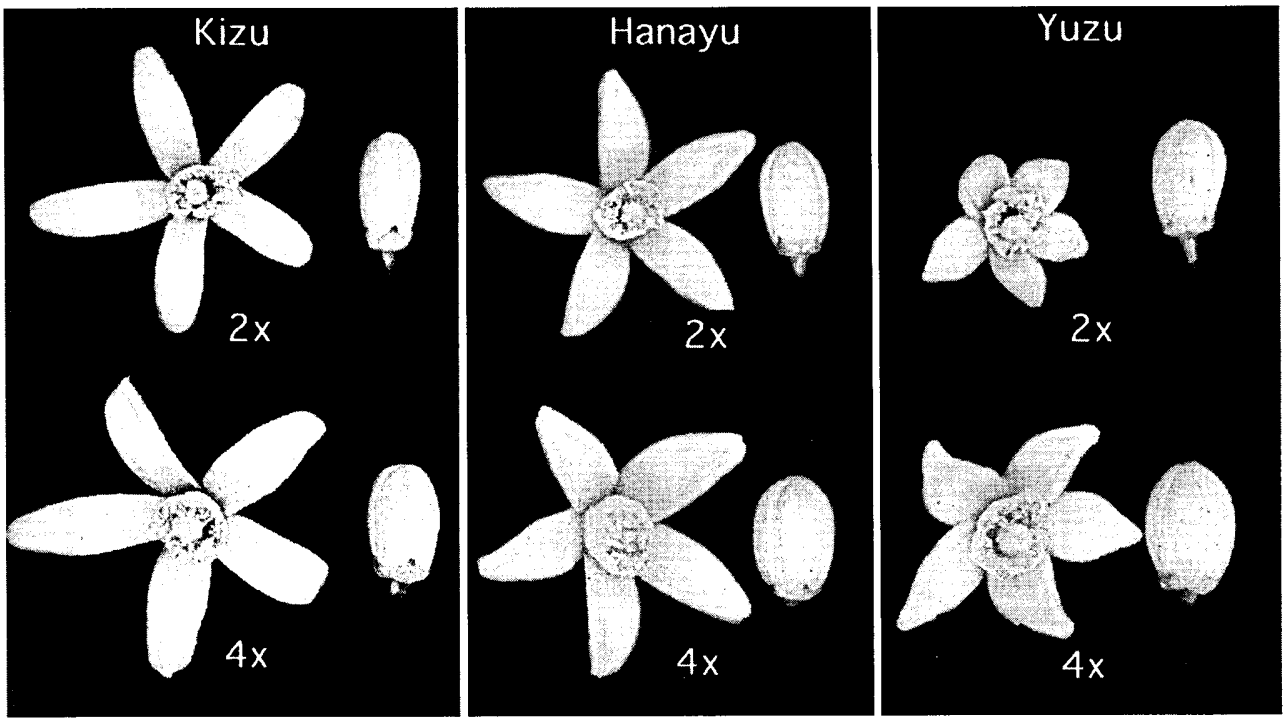

Fig. 2. Morphology of just-opened flowers and flower buds just before anthesis in colchicine-induced tetraploids (lower) and the original diploid (upper) 'Kizu', 'Hanayu' and 'Yuzu'.

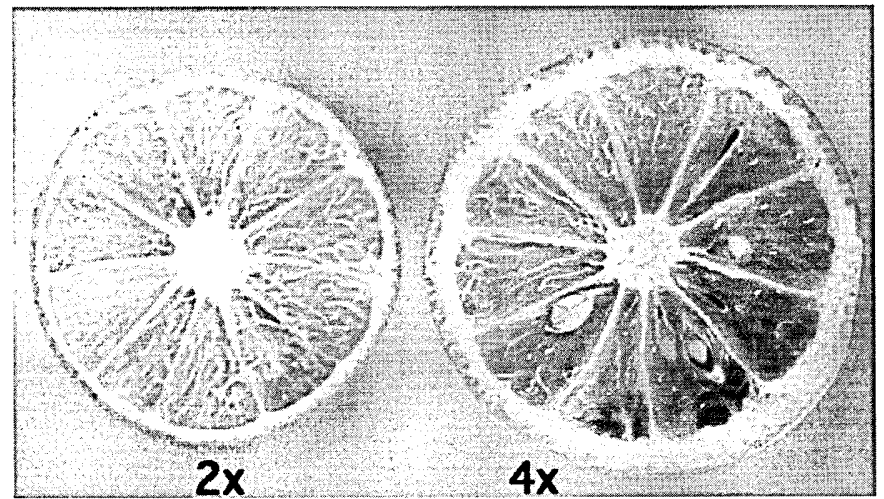

Fig. 3. Bisected mature fruits derived from diploid (left) and colchicine-induced tetraploid (right) 'Kizu'. Note the difference of rind thickness and fruit size between $2 \mathrm{x}$ and $4 \mathrm{x}$ fruits. 
Table 3. Leaf and fruit characteristics in colchicine-induced tetraploid plants and their original diploid acid citrus cultivars.

\begin{tabular}{|c|c|c|c|c|c|c|c|c|}
\hline Plant No. ${ }^{a}$ & $\begin{array}{l}\text { Weight } \\
\text { of fruit } \\
\text { (g) }\end{array}$ & $\begin{array}{l}\text { Rind } \\
\text { thickness } \\
(\mathrm{mm})\end{array}$ & $\begin{array}{l}\text { Leaf } \\
\text { width } \\
(\mathrm{mm})\end{array}$ & $\begin{array}{l}\text { Leaf } \\
\text { length } \\
(\mathrm{mm})\end{array}$ & $\begin{array}{c}\text { Leaf } \\
\text { shape } \\
\text { index }\end{array}$ & $\begin{array}{c}\text { Number } \\
\text { of seeds } \\
\left(\text { No. }{ }^{\circ}\right)\end{array}$ & $\begin{array}{c}\text { Weight } \\
\text { of seed } \\
\text { (mg) }\end{array}$ & $\begin{array}{c}\text { Ploidy } \\
\text { of } \\
\text { seedling }\end{array}$ \\
\hline \multicolumn{9}{|l|}{ Yuzu } \\
\hline Original $2 \mathrm{x}$ & 114 & 5.0 & 3.3 & 6.8 & 0.49 & $24.3(0.9)$ & 290 & $2 x$ \\
\hline $0.1-12-$ No.1 & 159 & 6.5 & 4.2 & 6.9 & 0.61 & $11.3(3.0)$ & 330 & $4 \mathrm{x}$ \\
\hline \multicolumn{9}{|l|}{ Hanayu } \\
\hline Original $2 \mathrm{x}$ & 40 & 3.9 & 4.0 & 9.2 & 0.44 & $6.8(0.2)$ & 371 & $2 \mathrm{x}$ \\
\hline $0.1-6-$ No. 1 & 87 & 5.6 & 4.8 & 8.5 & 0.56 & $10.8(2.6)$ & 423 & $4 \mathrm{x}$ \\
\hline $0.2-6-$ No. 4 & 73 & 5.5 & 5.4 & 9.6 & 0.57 & $17.5(1.0)$ & 406 & $4 \mathrm{x}$ \\
\hline $0.2-6-$ No.5 & 64 & 5.8 & 4.8 & 8.4 & 0.57 & $10.0(1.0)$ & 390 & $4 \mathrm{x}$ \\
\hline \multicolumn{9}{|l|}{ Kizu } \\
\hline Original $2 \mathrm{x}$ & 80 & 2.7 & 3.8 & 7.9 & 0.48 & $4.3(0.0)$ & 380 & $2 \mathrm{x}$ \\
\hline $0.4-6-$ No. 2 & 141 & 4.8 & 4.8 & 8.1 & 0.60 & $5.4(0.6)$ & 500 & $4 \mathrm{x}$ \\
\hline $0.2-6-$ No. 3 & 84 & 4.3 & 5.3 & 8.2 & 0.65 & $2.6(1.6)$ & 500 & $4 \mathrm{x}$ \\
\hline $0.1-6-$ No. 5 & 120 & 4.4 & 4.9 & 7.7 & 0.63 & $3.5(1.0)$ & 505 & $4 \mathrm{x}$ \\
\hline $0.2-6-$ No.7 & 115 & 3.9 & 5.7 & 8.7 & 0.62 & $3.6(0.0)$ & 478 & $4 \mathrm{x}$ \\
\hline $0.1-$ No. $1^{\mathrm{e}}$ & 148 & 5.3 & 4.3 & 6.8 & 0.62 & $6.0(2.0)$ & 500 & $4 \mathrm{x}$ \\
\hline
\end{tabular}

${ }^{a}$ Number indicates colchicine concentration (\%) followed by exposure time to colchicine (hr) and individual seedling number. ${ }^{b}$ Leaf width / leaf length. ${ }^{\mathrm{c}}$ Number of small plumped seeds supposed to be triploid (Wakana et al., 1982). The number of perfect seeds includes the number of small seeds. ${ }^{\mathrm{d}}$ The seedlings were derived from sowing of large perfect seeds. e Tetraploid plant 0.1-No.5 was directly induced as a bud sport by the treatment of a solution of $0.1 \%$ colchicine on an axial bud of intact shoot without immersion treatment and subsequent grafting.

\section{DISCUSSION}

The present study demonstrates that immersion of one-year-old shoots with sprouting axillary buds in colchicine solution and subsequent top grafting of the immersed shoots on adult trees is a very useful and efficient technique for the production of tetraploid forms of desired diploid Citrus cultivars, since the induced tetraploid plants set fruits two to four years after the top grafting and is directly used for crossings to produce triploid hybrids. The diploid Citrus cultivars used in this study are polyembryonic, and their tetraploid forms induced by colchicine also showed the same degree of polyembryony in the seeds. The induced tetraploid forms of 'Yuzu' and 'Hanayu' produced seeds of which about half were monoembryonic, suggesting the tetraploids are useful not only for pollen parents but also for seed parents. However, tetraploid form of 'Kizu' is available only for a pollen parent, since it exhibited high polyembryony as the original diploid did.

Tetraploid forms of diploid Citrus cultivars have been derived from nucellar seedlings (Soost and Cameron, 1975; Soost, 1987), through in vitro culture of undeveloped ovules of polyembryonic cultivars (Gmitter and Ling, 1991) and through protoplast fusion in vitro with embryogenic callus induced from polyembryonic citrus ovules (Kobayashi and Ohgawara, 1988; Grosser and Gmitter, 1990). These tetraploid seedlings require long 
years of vegetative growth to leach their adult phase because of their long juvenile periods. Furthermore, these tetraploids, which are either nucellar or nucellar with fused nuclei, are available only for a pollen parents because of their high degree of polyembryonic ability. Oiyama and Okudai (1986) induced tetraploid plants through micrografting of colchicine-treated shoot apex of axillary buds in monoembryonic citrus cultivars. However, this method also requires long time up to flowering of the grafted plants on seedlings. Hence, the present method of colchicine treatment and top working is superior to these reported ones to develop triploid breeding in acid citrus.

The high colchicine concentration (0.8\%) depressed shoot development from the treated axillary buds and resulted in failure of top working in two cultivars used in this study, whereas the low concentrations $(0.05-0.20 \%)$ are considered to have no effect on the shoot development and top working. Differential sensitivity to the $0.4 \%$ colchicine treatment was observed among cultivars, i.e., it was suppressive for shoot meristem development in axillary buds of 'Hanayu' and 'Kizu'. Thus, this concentration is not widely applicable to produce tetraploid forms of diploid Citrus cultivars, although one tetraploid plant was recovered from one axillary bud treated with this concentration in 'Kizu' and 'Yuzu'. The appropriate exposure time to colchicine was 12 hours for 'Yuzu', while in 'Hanayu' and 'Kizu' many tetraploid plants were recovered by the exposure time of six hours with a maximum recovery rate of $40 \%$. Hence, it is referred from these results that the appropriate exposure time of trimmed shoots with sprouting axillary buds to colchicine solution is $6-12$ hours and that the concentration is $0.1-0.2 \%$.

The axillary buds forming on shoots of 'Hanayu', 'Yuzu' and 'Kizu' are the compound buds composed of a thorn (a main bud for 'Kizu') and an accessory bud (a first bract leaf axillary bud initiating on the base of first bract leaf of the main bud or thorn) with two secondary accessory buds developing at the first and second bract leaf axils of the accessory bud (Wakana, 2002). Because of the development of more than two shoots from one compound axillary bud in these acid citrus cultivars, the $2 \mathrm{x}$ and $4 \mathrm{x}$ shoots are considered to originate from two buds within one compound axillary bud treated with colchicine.

Disappearance of sectorial-chimera-like or mixoploid-like morphology in some shoots by five year after grafting suggests that these shoots are unstable to maintain their structure. Conversely, it is concluded that the successfully induced tetraploid plants have stable shoot structure. Although ploidy level in each of the three germ layers of the shoots was not determined in this study, the morphological and cytological data indicate that the colchiploids are stable tetraploid plants, at least, whose LII layer is tetraploid. Since the reproductive cells originate from the LII layer (Frost and Krug, 1942; Tilney-Vassett, 1982), these colchiploids or tetraploid forms of diploid cultivars will be effectively and directly utilized for triploid breeding programmes to develop triploid seedless acid citrus cultivars.

\section{REFERENCES}

Barrett, H. C. 1974 Colchicine-induced polyploidy in Citrus. Bot. Gaz., 135: 29-34

Esen, A. and R. K. Soost 1971 Unexpected triploids in Citrus: their origin, identification and possible use. J. Hered., 62: 329-333

Frost, H. B. and C. A. Krug 1942 Diploid-tetraploid periclinal chimeras as bud variation in Citrus. Genetics, 27: 619-34 
Geraci, G., A. Esen and R. K. Soost 1975 Triploid progenies from $2 \mathrm{x} \times 3 \mathrm{x}$ crosses in Citrus cultivars. J. Hered., 66: $177-178$

Gmitter, F. G. and X. B. Ling 1991 Embryogenesis in vitro and nonchimeric tetraploid plant-recovery from underdeveloped citrus ovules treated with colchicine. J. Amer. Soc. Hort. Sci., 116: 317-321

Grosser, J. W. and F. G. Gmitter, Jr. 1990 Somatic hybridization of citrus with wild relatives for germplasm enrichment and cultivar development. HortScience, 25: 147-151

Kobayashi, S. and T. Ohgawara 1988 Production of somatic hybrid plants through protoplast fusion in Citrus. JARQ, 22: 181-188

Oiyama, I. and N. Okudai 1986 Colchicine-induced autotetraploid plants through micrografting in. monoembryonic citrus cultivars. Japan. J. Breed., 36: 371-376

Park, S. M., M. Hiramatsu and A. Wakana 1999 Aneuploid plants derived from crosses with triploid grapes through immature seed culture and subsequent embryo culture. Plant Cell, Tissue and Organ Culture, 59: 125-133

Soost, R. K. $1987 \quad$ Breeding citrus-Genetics and nucellar embryony. In "Improving vegetatively propagated crops" edited by Abbott, A. J. and R. K. Atkin, Academic Press, London, pp. 83-110

Soost, R. K. and J. W. Cameron 1975 Citrus. In "Advances in Fruit Breeding" ed. by J. Janick and J. N. Moore, Purdue University Press, West Lafayette, pp. 507-540

Soost, R. K. and J. W. Cameron 1980 'Oroblanco', a triploid pummelo-grapefruit hybrid. HortScience, 15: $667-669$

Soost, R. K. and J. W. Cameron 1985 'Melogold', a triploid pummelo-grapefruit hybrid. HortScience, 20: 1134-1135

Tachikawa, T. 1971 Investigations on the breeding of citrus trees IV On the chromosome numbers in Citrus. Bull. Shizuoka Prefect. Citrus Exp. Stn., 9: 11-25 (in Japanese with English summary)

Tilney-Vassett, R. A. E. 1982 Plant chimera. Edward Arnold Publishers, London (Great Britain), pp. 199

Wakana, A. 2002 Training and Pruning. In "Saishin Kajyuengeigaku (The Newest Pomology)" ed. by F. Mizutani, Asakura Shoten, Tokyo, pp. 200-222 (in Japanese)

Wakana, A., M. Iwamasa and S. Uemoto 1981 Seed development in relation to ploidy of zygotic embryo and endosperm in polyembryonic citrus. Proc. Int. Soc. Citriculture, 1: 35-39 